\title{
Pharmacological Cardioversion of Atrial Fibrillation In Nepalese Population
}

\author{
Bharat Rawat, Prof D.B Karki, S,C Jha, Jesson Gurung, Subhash \\ Acharya, Harminder Singh Sodhi, Minaima Pandey, Sudarshan Dhonju, \\ Rajib Pande
}

\section{Background:}

Intravenous Procainamide and Oral Flecainide are often used for cardioversion of Paroxysmal Atrial Fibrillation (AF). Hypertensive patients may have problems of proarrythmias with these agents and Intravenous Amiodarone may be an effective safer alternative. The utility of Intravenous Amiodarone in such group of patients in the Himalayan kingdom of Nepal has never been assessed.

\section{Methods}

76 patients with hypertension and non-valvular Atrial Fibrillation lasting for more than 24 hours were admitted for pharmacological cardioversion. Patients with valvular heart disease, cor-pulmonale, acute coronary event, left ventricular ejection fraction of less than $40 \%$, and $\mathrm{AF}$ with slow ventricular rate were excluded. Patients with AF duration more than 48 hours or with AF of uncertain age were given a prior three weeks of anticoagulation. Those who were not already on oral anticoagulation were put on intravenous heparin with APTT maintained at 1.5 to 2.5 times the control. Intravenous amiodarone was given in the loading dosage of $15 \mathrm{mg} / \mathrm{min}$ over 10 minutes, followed by $1 \mathrm{mg} / \mathrm{min}$ in the next 6 hours \& maintained at $0.5 \mathrm{mg} / \mathrm{min}$ for the next 42 hours. Elective DC- cardioversion was planned if patient was still-in AF at the end of 48 hours.

\section{Results}

$54 \%$ ( 41 out of 76 ) of overall patients \& $70 \%$ (32 out of 46 ) of the patients with AF of less than 48 hours duration reverted to normal sinus rhythm within 48 hours of intravenous amiodarone, $30 \%$ (23o Out of 76 ) patients were reverted with DC- cardioversion. None of the patients had any untoward effects of amiodarone. All the patients were discharged on the third day. 
- NEPALESE HEART JOURNAL •

\section{Conclusion:}

Intravenous amiodarone is a safe \& effective method of pharmacological Cardioversion of $\mathrm{AF}$ in hypertensive patients particularly if it is of less than 48 hours duration.

NORIMCG Escorts International Hospital. Kathmandu, Nepal. 